medicine or the physician this book would not go far enough.

Many illustrative electrocardiographic tracings are given and some useful notes on the clinical aspects of the disorders. Although the practitioner is encouraged to diagnose the arrhythmias at the bedside, he is not expected to hear atrial sounds, count venous waves in the neck, or be deluded into thinking that he should always be able to distinguish atrial fibrillation from multiple ectopic beats without an electrocardiograph.

Practical notes on treatment are given with each section. However, one views with disquiet the type of medical practitioner for whom this book is designed, using many of the reversion techniques, when without a good deal of experience. The American general practitioner may have more opportunity for using such drugs as quinidine and procainamide, but his British counterpart sees little of his patient's treatment in hospital.

Thus to the practitioner who wishes to know more of arrhythmias without becoming involved in electrocardiography this book will appeal.

\section{The Anatomy of the Eye and Orbit}

Eugene WolfF. Fifth edition. Revised by R. J. LAST, M.B., B.S., F.R.C.S.ENG. 438 illustrations (54 coloured). Pp. viii +500 , London: H. K. Lewis. $£ 44$ s.

This book was first published in 1933 and following the death of Eugene Wolff the fifth edition has been revised by Professor R. J. Last. It presents a clear account of the macroscopic and microscopic structure, development and comparative anatomy of the visual apparatus. With advances in technique and the introduction of the electron microscope anatomy is a growing subject.

There are some omissions in the book, such as recent work on the oculo-motor nucleus and the blood supply of the optic nerve head.

The book is well produced and richly illustrated. Most of the author's original black and white drawings have been retained.

Professor Last has preserved the spirit and pattern of the original work and it can be highly recommended to students of ophthalmology and to those interested in the anatomy of the visual apparatus.

\section{Essentials of Neurology}

John N. Walton, M.D., M.R.C.P. Pp. xvii +422 , illustrated. London: Pitman Medical Publishing Co. 196r. 30 s.

The need for a brief text book of neurology has been felt for some time but it is not certain, however, that the need has been completely fulfilled. Dr. Walton's book is intended for undergraduate and postgraduate students, and for practitioners. Compression has been achieved partly by limiting the scope of the work, which is written from the standpoint of the bedside neurologist. Accounts of normal and disordered physiology, and of pathology, have largely been omitted and are only mentioned when 'absolutely necessary for an understanding of clinical principles '. Nevertheless, the book is, in general, remarkably comprehensive. An exception is the chapter on psychiatric disorders which is so sketchily written that its inclusion seems hardly profitable. The reviewer also objects, on semantic grounds, to its entitlement as 'Disorders of the Mind'.

With regard to the general plan of the book, Dr. Walton begins by considering some useful general principles, and follows this by chapters on the investigation of the neurological patient. The remainder of the first half of the book consists of an analysis of the principal symptoms and signs produced by diseases of the nervous system. In the second half, he presents a description of individual diseases and syndromes and concludes with a chapter, perhaps a little too abbreviated, on treatment in neurology. The style is fluent, making the work surprisingly readable in view of the condensation of material that has been achieved.

Dr. Walton's 'Essentials of Neurology' represents a useful addition to the teaching of neurology.

Advances in Biology of Skin: Vol. I-Cutaneous Innervation

Edited by William Montagna. Pp. xii +203 , with 118 illustrations. Oxford, London, New York, Paris: Pergamon Press. 1960. 63 s.

This publication represents the proceedings of the Brown University Symposium on the Biology of the Skin held in 1959. Recent years have yielded innervation as newer histological and electrophysiological techniques have been applied. The participants in this symposium include several of those who have contributed to these advances.

Accounts of the histological aspects of cutaneous innervation have been provided by Malcolm Miller and his associates, R. K. Winkelmann and William Montagna. The high quality of the photographic plates illustrating these articles is to be commended. The changes in knowledge of cutaneous neurohistology that have accrued over the past two decades have given rise to problems concerning the mechanism of cutaneous sensibility. Fxperiments relating to a possible solution are described by Graham Weddell. There are also two chapters by G. H. Bishop on the relation of nerve fibre size to modality of sensation and to the organization of the central paths of the cutaneous afferents, which are an interesting synthesis of physiological and anatomical studies. Other articles are on autonomic innervation and on the mechanism of itch.

Although much of the material included has been published elsewhere, this book provides a useful compilation of recent work in this important field.

\section{The Practical Management of Head Injuries}

John M. PotTer, M.A., M.B., B.CHIR.(CANTAB.), F.R.C.s. Pp. xii +84 , illustrated. London: LloydLuke (Medical Books). I96 I. I2s.

This short account of the management of head injuries begins by considering the examination and assessment of the patient in the casualty department and follows with an account of care in the ward. A chapter is devoted to the treatment of complications and finally one to the important question of rehabilitation after head injuries. It is lucidly written in an informal and engaging style. The author has undoubtedly succeeded in providing a book that, to quote from the preface, is ' a practical guide . . . not designed to help those who merely wish to pass surgical examinations '.

\section{A Manual of Psychiatry}

K. R. Stallworthy, M.B., Ch.B., Diploma Psychological Medicine. Fifth edition. Pp. 386. Christchurch, New Zealand: N. M. Peryer. 1961. 305.

Both Dr. Stallworthy and the writer of the foreword suggest that this 'Manual of Psychiatry' is suitable for students, general practitioners and nurses. This is not so. It might possibly suffice to acquaint a long-established general practitioner whose psychiatric education had been neglected as an undergraduate with the 
principles of the subject but it is certainly not suitable for the medical student. It is surprising that the author feels that the needs of the psychiatric nurse and the medical student could ever be satisfied by the same text book.

The book is characterized by a humane approach to the psychiatric patient which is so characteristic of the way of life in New Zealand, where Dr. Stallworthy lives and works. Equally characteristic is the manner in which it reflects the psychiatric attitudes of the home country, due regard being paid to the pathophysiology as well as the psychopathology of mental illness. It is written in simple language and in an easily comprehensible style but in spite of references to the latest neuroleptic and antidepressant drugs and to the abnormal chromosome pattern in mongols, there is a somewhat old-fashioned air about the volume which is not dispelled by lengthy accounts of deep insulin treatment, prolonged narcosis, hydrotherapy, the malarial treatment of general paresis and of the stringent precautions to be taken against suicide in depressed patients.

There is much that is good about this book but it is marred by a number of imprecise and loose statements; 'the rare temporal lobe epilepsy'; 'hallucinations occur only in the psychoses '; 'Korsakow's psychosis is an organic dementia . . . with an unusual tendency to confabulation'; 'the eunuch is impotent'. The chapter on epilepsy in particular is outmoded and the recommendation in the case of an attack of grand mal ' if he has teeth, try to open his mouth and insert some object' is downright dangerous.

There is a pressing need for a good text book of psychiatry for nurses and it is to be hoped that the project sponsored by the R.M.P.A. will fulfil this requirement. Until some such volume is available the psychiatric nurse in training might do worse than rely upon Dr. Stallworthy's manual.

\section{Nervous Inhibition: Proceedings of the Second Friday Harbor Symposium}

Editor: Ernest Florey. Pp. 475. Oxford, London, New York and Paris: Pergamon Press. 196r. £5.

When a group of international experts gather to discuss one small aspect of their field of work, it is unlikely they will have much to say of interest to the general reader. Moreover, their discussion is often couched in language which is barely intelligible to those outside the field. This cannot be said of the present symposium for, though the subject may not have general appeal, the contributions are lucid and to the point, and the illustrations are of unusually high quality.

The phenomenon of inhibition of an actual or potential activity in the nervous system has long been recognized, but the neural mechanisms by which this is achieved have equally long been obscure. Now, however, there can be no doubt that certain neurons are specifically concerned with inhibiting the activity of other,neurons. How this is achieved is to a large extent described in the various papers included here. There are, of course, many problems as yet unsolved. But within these pages we have a succinct description of the present position given by those best qualified, namely, people who are actively engaged in the study of the problem. There are also clear indications as to whef the future lies as, for example, in the paper on the inhibitory transmitters.

It cannot be expected that a book of this kind w have a wide sale, especially in view of its cost, but those interested in neurophysiology will find it a valuab book to have. The large number of references and the good index increases its value.

\section{Surgery of Trauma in the Tropics}

R. L. BAtTen. Pp. viii +234 , illustrated; Londorad Edward Arnold. r 961 . 35 s.

This short book is directed especially to those rê? sponsible for the treatment of trauma in smaller tropice्यु hospitals. Surgical practice in such circumstances is greatly influenced by poor communications, lack of special centres, uneducated population, scarcity of bloos for transfusion and the climate.

The book is short and includes a chapter on anæsthes? in its 234 pages. The discussion is therefore brief, bet the treatment advised is orthodox and full of commoge sense. There are some notable omissions, viz: surgical emphysema, acute renal failure and fat embolism.

The last 14 pages are devoted to instruments and appliances. Perhaps this space would be better occupied by a description of the shock room, the method of examination of a patient with multiple injuries and 9 discussion of the priority of treatment of the various injuries. The index is rather brief. The book is well illustrated and there is a short bibliography at the end of each chapter.

\section{Histology}

ARThUR W. HAM, M.B., F.R.s.c., and ThomaK LEESON, M.A., M.D., B.CH.(CANTAB.). Fourth edițīild Pp. xv + 942, illustrated. London: Pit Medical Publishing Co. 196r. £4 5 s.

Four editions in less than twelve years should sufficient recommendation for any standard work, and are especially remarkable in the relatively static field of histology. Ham's Histology owes its success to th functional presentation of cellular structure close related to physiological and pathological behaviour with this vital approach, anatomy, physiology, and bio chemistry become linked and interdependent. This new edition, with Dr. T. S. Leeson as a co-authos amplifies the modern methods of investigating cellular structure and function, and the breakdown of the individual cell into recognizable components with specialized activity is becoming a textbook realit. Advances in histology nowadays follow advances medical and other biological sciences, and our increasing knowledge of the importance of 5-hydroxytryptaming and of gastrin calls for more space devoted to intestina argentaffin cells, and to the non-insulin secreting cells of the islets of Langerhans. Histologists working with the light microscope realize that they must re-lear their subject with the electron microscope and add tional electron micrographs and descriptions of fing structure are particularly welcome. As a textbook of pure and applied histology, this edition stands supremes it is beautifully produced and the price-so often 9 limiting factor in books originating from the New World-is most reasonable.

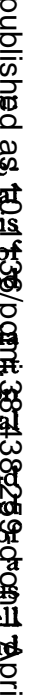

